\title{
Assessment the role of Platelet Rich Plasma in Follicular Unit Extraction Hair Transplantation
}

\author{
Mohamed Abdulaziz ${ }^{1, *}$ MSc, Osama Al-Shahat ${ }^{1}$ MD and Ahmed Taha ${ }^{1}$ MD
}

*Corresponding Author:

Mohamed Abdulaziz

MohamedAli.6@azhar.edu.eg Received for publication May 3, 2020; accepted June 5, 2020; published online June 6 , 2020 .

Copyright 2020 The Authors published by Al-Azhar University, Faculty of Medicine, Cairo, Egypt. All rights reserved. This an openaccess article distributed under the legal terms, where it is permissible to download and share the work provided it is properly cited. The work cannot be changed in anyway or used commercially.

doi: 10.21608/aimj.2020.29351.1217

${ }^{I}$ Plastic \& Reconstructive Surgery and Burn Department, Faculty of Medicine, Al-Azhar University Cairo, Egypt.

\begin{abstract}
Background: Hair transplant surgery using follicular unit extraction technique (FUE) is a common surgical procedure for the treatment of severe hair loss; this study aimed to study the effect of Platelet-rich plasma and assess its role in follicular unit extraction hair transplantation.
\end{abstract}

Material and Methods: A prospective randomized controlled study was conducted among 40 patients suffering from alopecia and candidate for follicular unit extraction (FUE) hair transplantation, with age between 25 years and 60 years in group androgenic alopecia; with no age limitation in cicatricial alopecia.

Results: Functional and aesthetic outcomes were achieved from adding PRP regimen to follicular unit extraction hair transplantation mainly in cases presented to us with post cicatricial alopecia. The improvement noticed in early recovery time \& increase in density, with no statistical difference in patients presented to us with androgenic alopecia.

Conclusion: PRP therapy after hair transplantation is beneficial in giving faster density with the reduction in recovery period post cicatricial alopecia, with no benefit in FUE hair transplantation in cases with androgenic alopecia.

Keywords: Hair Restoration; PRP and Hair; Post Cicatricial alopecia.

Authorship: All authors have A substantial contributions to the article, However first, third Authors described and practice the technique of follicular unit extraction hair transplantation with intraoperative and post follow up injection of PRP

Disclosure: The authors have no financial interest to declare in relation to the content of this article. The Article Processing Charge was paid for by the authors.

\section{INTRODUCTION}

Hair is very important in character and personality. Hair shafts are very important in functions like thermoregulation, collection of sensory information, protection against environmental trauma, social communication, and camouflage. Each one of humans displays an estimated total number of 5 million hair follicles (HF), of which 80,000150,000 are located on the scalp. ${ }^{1}$

Hair transplant surgery has made significant advances and improvements over the past 25 years that has resulted in highly satisfied patients. The movements from mini- and micro-grafting techniques to the now-standard follicular grafting techniques have led to more aesthetically pleasing and natural appearance of transplanted hair. While the strip technique was the most practiced method of donor harvest. ${ }^{2}$ The final cosmetic outcomes did not depend only on the graft type (single hair on grafts or follicular units). The survival rate of the transplantation and the skills of the surgeon but also on the number of grafts can transplant. Thus, advances towards increasing the number of complete follicular units harvested by reducing the follicular transection rates (FTR) help to achieve the optimum desired result. ${ }^{3}$

There are many factors beneficial in achieving good results with hair transplantation surgeries; finding the optimal storage solution and the most effective. ${ }^{4}$

Hair growth has an individual cycle. During the first 2 weeks of implantation, the catagen phase occurs, marked by an inflammatory process in which redness in the scalp and shedding of the hair shaft is common. The patient then enters the telogen phase, 
which lasts between 3 and 4 months. This is followed by the latency period, which precedes the third phase, anagen. During this phase, the future hair begins to grow. ${ }^{5}$

Intra-operative injection of PRP is beneficial in giving faster density, reducing the catagen loss of transplanted hair, early recovery of the skin, the faster appearance of new anagen hair in FUE hair transplantation. ${ }^{6}$

Cicatricial alopecia areas are poor graft recipients because of reduced blood perfusion in it. The percentage of grafted follicles that survive depends in great measure on the blood supply of the vascular bed. PRP is a rich source of anagen-maintaining factors, such as insulin-like growth factor 1 (IGF-1), basic fibroblast growth factor (bFGF), and vascular endothelial growth factor (VEGF). Injection of PRP has been demonstrated to improve cutaneous ischemic conditions and to increase vascular structures around hair follicles. ${ }^{7 \& 8}$

This work aimed to study the effect of Platelet-rich plasma and assess its role in follicular unit extraction hair transplantation.

\section{PATIENTS AND METHODS}

This study was done on 40 patients suffering from alopecia and candidate for follicular unit extraction (FUE) hair transplantation, with age between 25 years and 60 years in group androgenic alopecia; with no age limitation in cicatricial alopecia, from June 2017 to March 2020 Patients will be divided into two main groups;

Androgenic alopecia, the group I was 20 patients.

Post cicatricial alopecia, Group II was 20 patients. Every group will be divided into subgroup:

Subgroup (a) 10 patients will be managed by follicular unit extraction hair transplantation,

Subgroup (b) 10 patients will be managed by follicular unit extraction hair transplantation with adding Platelet-Rich Plasma (PRP) injection of $0.1 \mathrm{cc}$ for every square centimeter in the recipient scalp with the following regimen! 1 week postoperative; 2 weeks post-operative; 3 weeks postoperative; Then Each month for three consecutive months.

The evaluation was done by analysis of preoperative and postoperative of follicular unit extraction (FUE) hair transplantation and throughout the time of wound healing and complication management if occurred up to 6 months by Patient satisfaction questionnaire, scalp redness, hair density, length, direction \& texture by using Trichoscopy in the analysis.

\section{Ethical approval:}

An approved was obtained from the Ethical Research Board (ERB) of the Faculty of Medicine, Al-Azhar University, Cairo, Egypt. Before the study proceeding, all patients assigned informed consent after the obvious explanation of the possible adverse events.

\section{Operative Technique}

We had used in this study Follicular unit extraction hair transplantation based onmicromotor\& straight handpiece, Jewelers Micro Forceps (Extraction \& implantation), punches of size $0.85 \mathrm{~mm} \&$ needle holder with slits or blade knife no.11. (Figure 1-4)

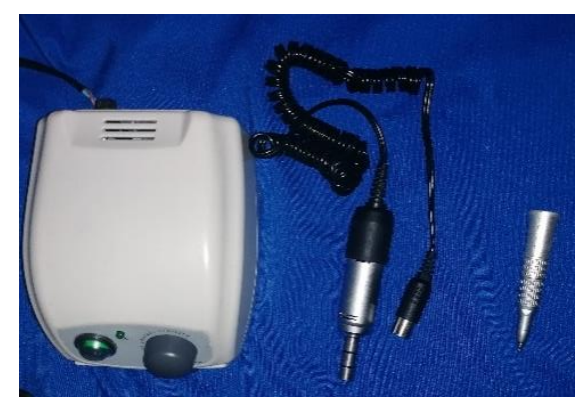

Fig. 1: Micromotor \& Handpeice

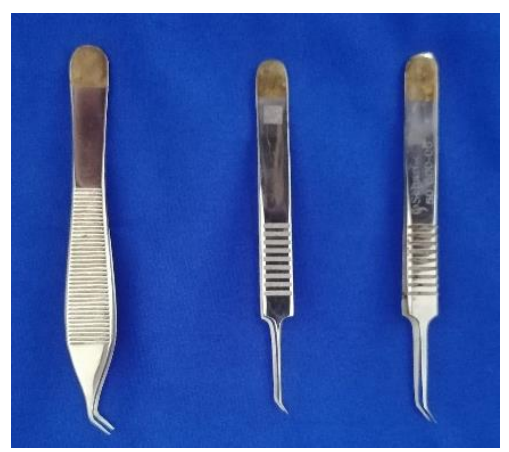

Fig. 2: Jewelers for extraction and implantation

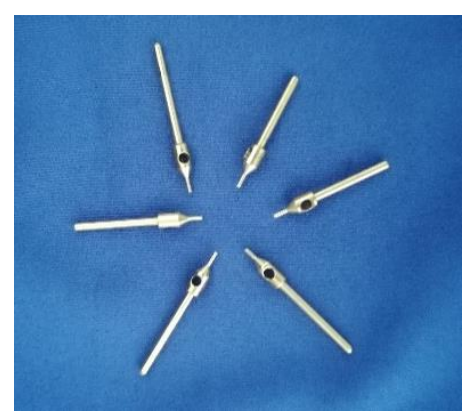

Fig. 3: Punches

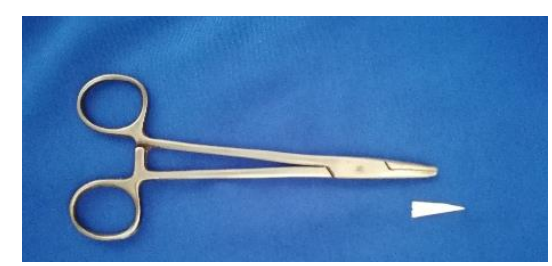

Fig. 4: Needle holder \& Blade knife No. 11 


\section{Preoperative Marking:-}

The new hairline as shown in (Figure 5). It should be created at a specific distance from the glabella, ranged from 7 to $9 \mathrm{~cm}$ from glabella.

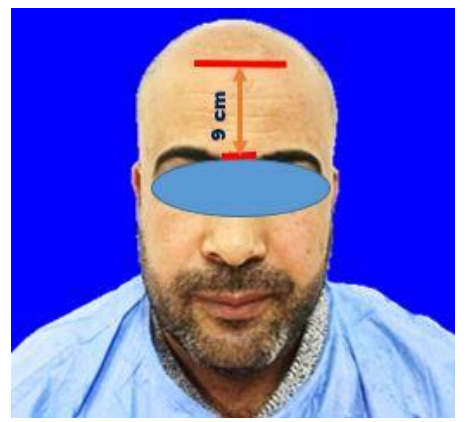

Fig. 5: Hair line design

\section{Donor site:}

Back \& sides of the scalp as shown in (Figure 6)

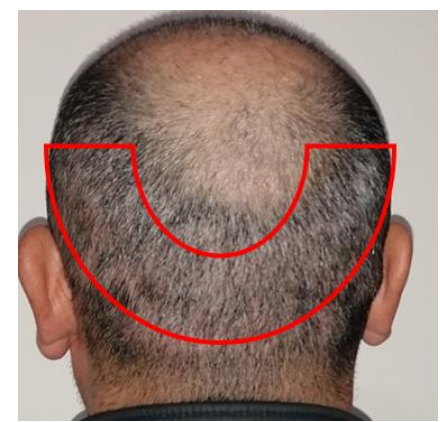

Fig. 6: Donor site

\section{Anesthesia:-}

Local anesthesia with $2 \%$ xylocaine concentration \& adrenaline $1 \mathrm{mg}$ for both donor and recipient.

\section{Donor site anesthesia}

For the ring block, at the donor site, we had prepared a solution of xylocaine $30 \mathrm{ml}$ with the addition of 30 $\mathrm{ml}$ normal saline with the concentration of adrenaline $(1: 1000)$ for donor $\&$ recipient block.

We inject at the posterior hairline for the prober block of the posterior occipital nerve.

\section{Recipient site anesthesia}

For ring block at the recipient site, we injected $3 \mathrm{~cm}$ on each side $\&$ when we are injecting we diffuse it medial and lateral to the supraorbital notch for prober block of both supraorbital and supra-trochlear nerve. To complete the ring block of the recipient site we injected at the hairline at the temporal region for the block of zygomatico-temporal nerve.

\section{Procedure:-}

\section{Harvesting of hair grafts}

Follicular units harvested by sharp punches we have used in this study $0.85 \mathrm{~mm}$ diameter sized punches. Storage of hair follicle grafts shown in in (Figure 7) We stored grafts in storage solution (cold saline) put at gauze during procedure time.

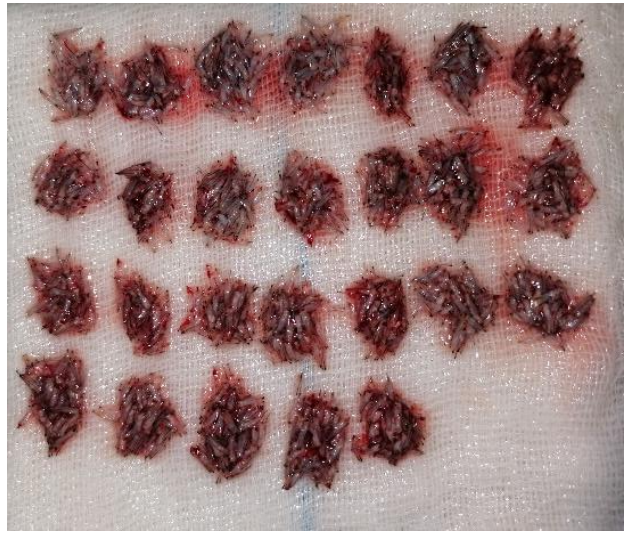

Fig. 7: Hair grafts

Creation of recipient sites and implantation of hair grafts

Creation of recipient sites and implantation of hair grafts

Creation of the recipient sites in the recipient area with blade width about $1.1 \mathrm{~mm}$ or with scalpel knife No. 11 carried on the needle holder.

Insertion of the graft with using of implantation jewelers.

\section{Dressing:-}

The dressing was exposed or closed according to site and patient tolerance, the closed dressing was removed from 2-4 days postoperatively.

\section{PRP preparation:-}

Double centrifugation process of PRP as shown at in (Figure 8)

The sample is initially collected in tubes that contain anticoagulants about $1 \mathrm{ml}$ of sodium citrate for every $10 \mathrm{ml}$ of blood.

The PRP is obtained from a sample of patients' blood drawn at the time of treatment. A $30 \mathrm{cc}$ venous blood draw will yield 3-5 cc of PRP, a double centrifugation process of PRP, the sample is initially collected in tubes that contain anticoagulants about $1 \mathrm{ml}$ of sodium citrate for every $10 \mathrm{ml}$ of blood.

The first spin step was performed at $2500 \mathrm{rpm}$ for 4 to 5 minutes for separation of whole plasma from RBCs.

For the production of pure PRP (P-PRP), the upper layer and superficial buffy coat are transferred to an empty sterile tube.

The 2nd spin step was performed at 3500 to 4000 rpm for 20 to 25 minutes for sedimentation of buffy coat and creation of PRP.

The upper portion of the volume that is composed mostly of PPP (platelet-poor plasma) is removed. Pellets are homogenized in lower $1 / 3 \mathrm{rd}(5 \mathrm{ml}$ of plasma) to create the PRP (Platelet-Rich Plasma). Clinical cases presented in in (Figure 9-14) 


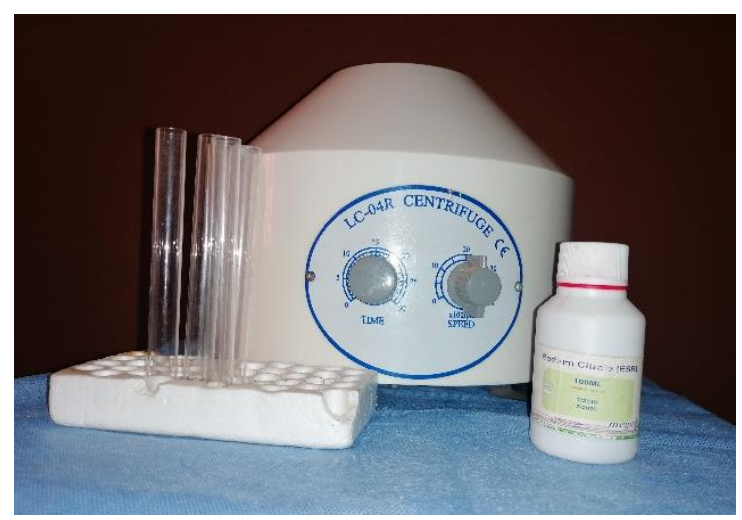

Fig. 8: Centrifuge, tubes \& sodium citrate
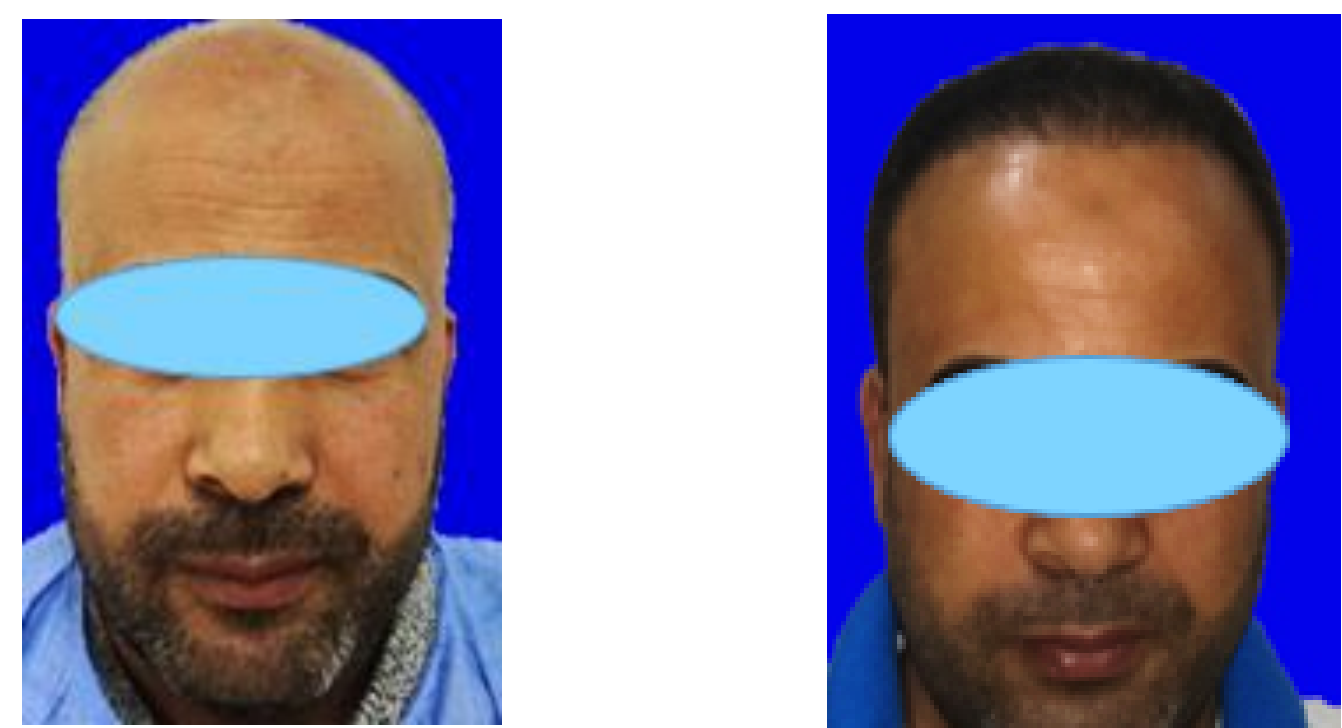

Fig. 9: Front view pre-operative and $6^{\text {th }}$ months post-operative.
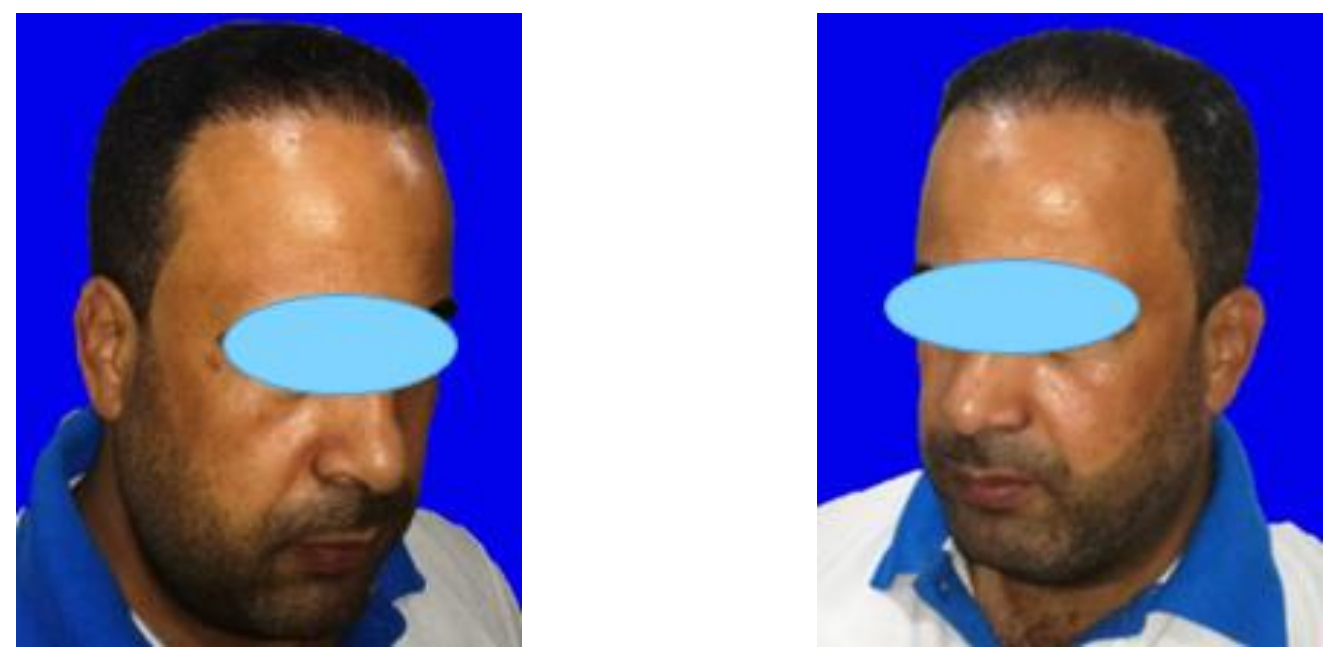

Fig. 10: Case 1 Right lateral and Left Lateral views $6^{\text {th }}$ months' post-operative 

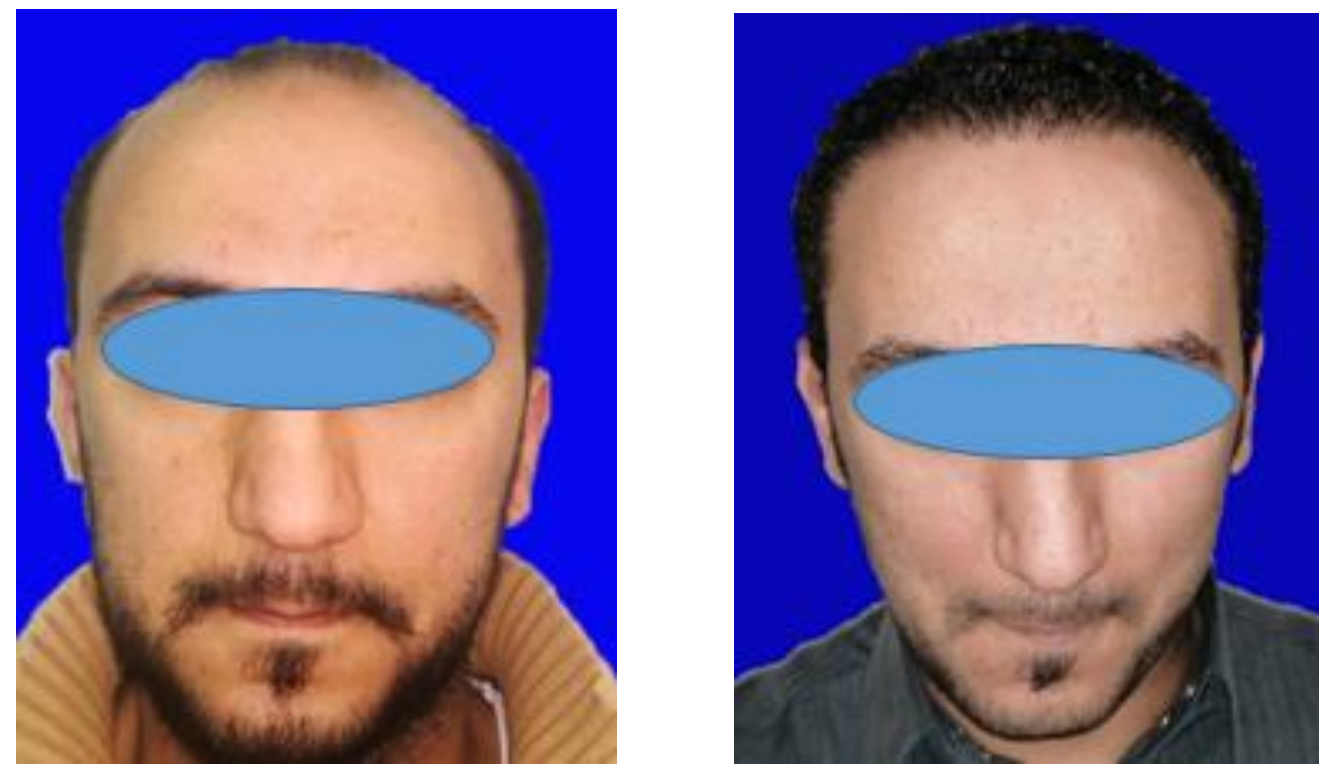

Fig. 11: Case 2 Front view pre-operative and $6^{\text {th }}$ months post-operative.
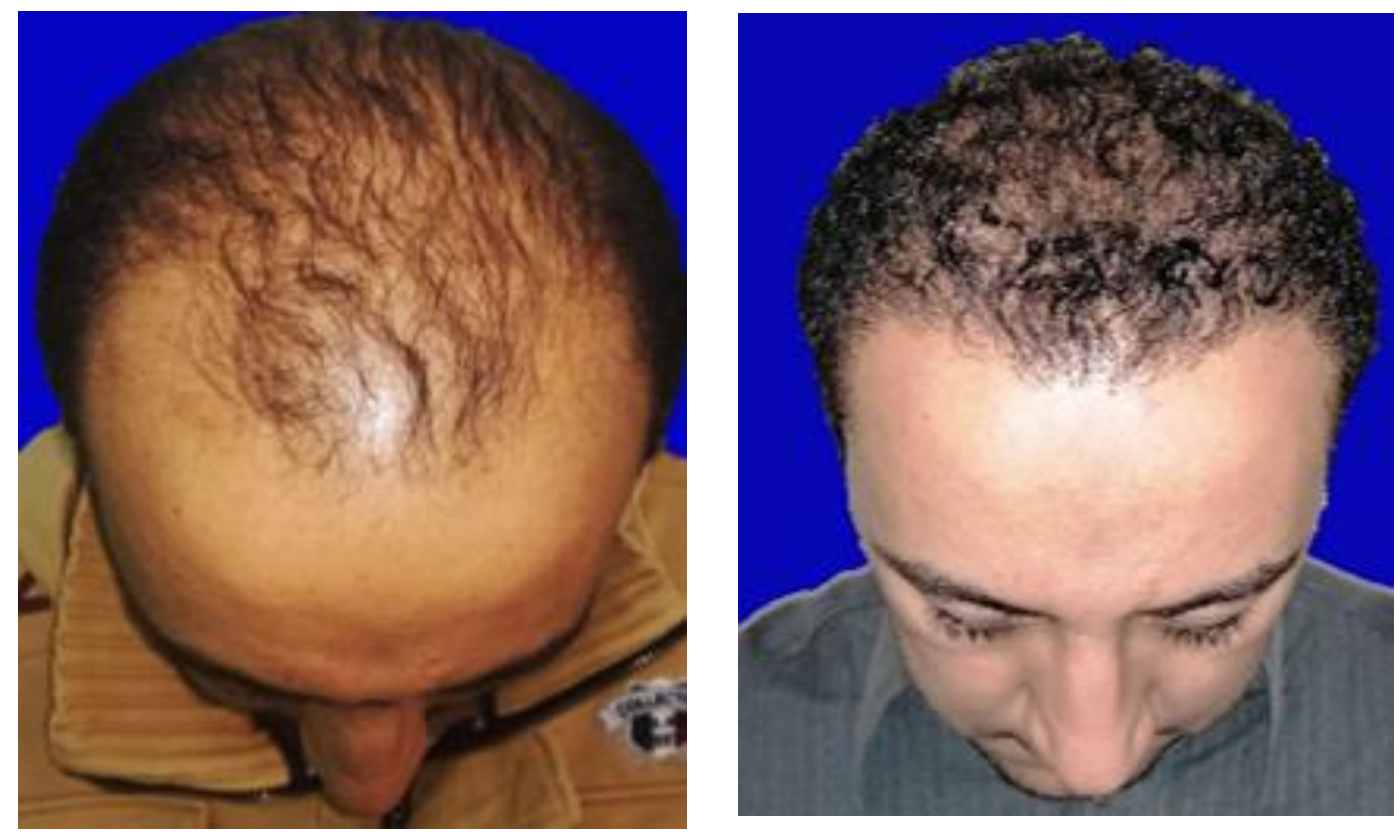

Fig. 12: Case 2 Basal preoperative and $6^{\text {th }}$ months post-operative 

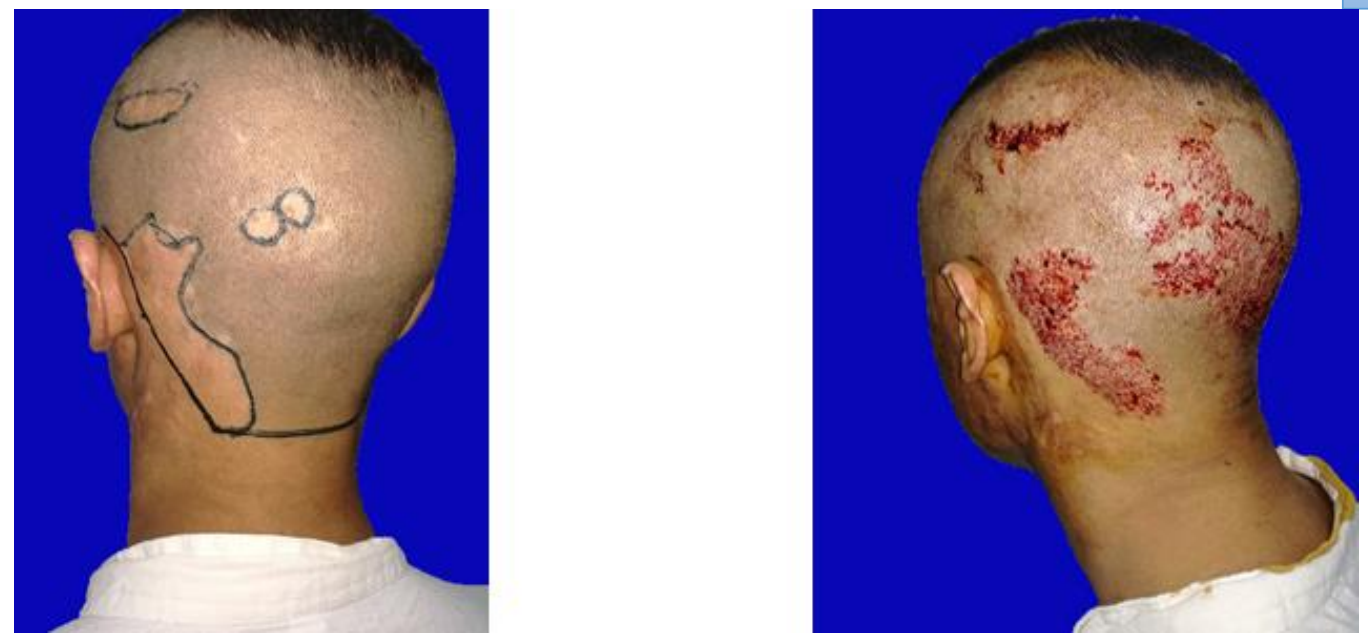

Fig. 13: Case 3Back view pre-operative and immediate post-operative.
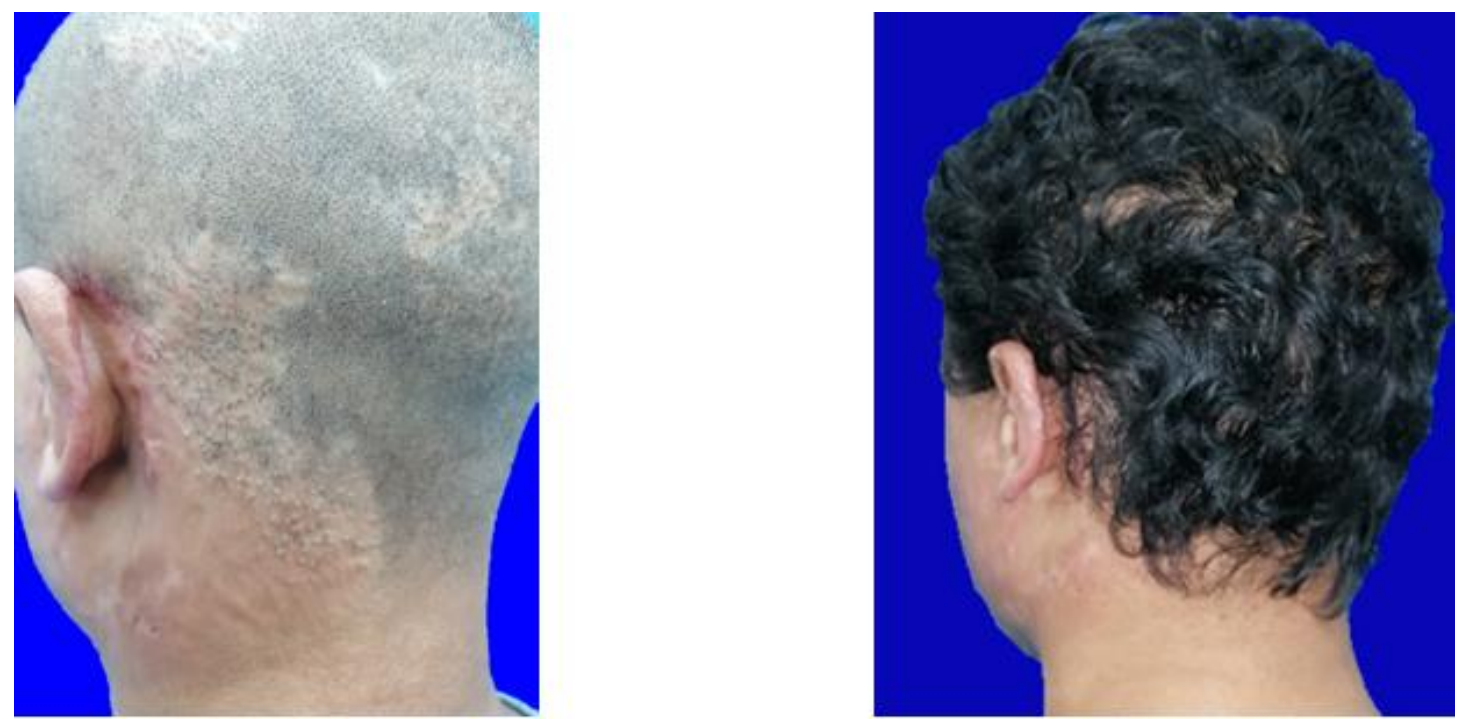

Fig. 14: Case 3the left photo for 3 months post-operative and the right photo for $6^{\text {th }}$ months post-operative
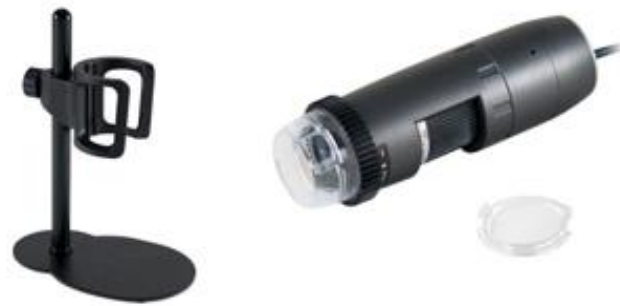

A

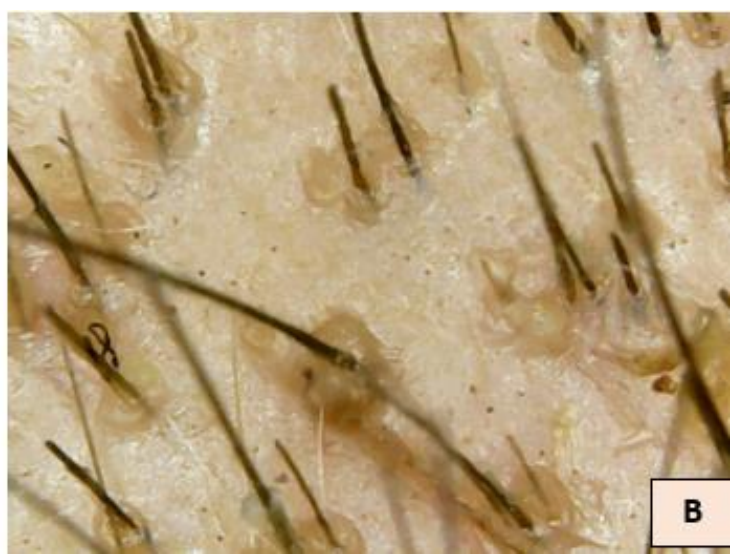

Fig. 15: A- Trichoscope with magnification power (x50) to (x200). B- Trichoscopic image 3 months postoperative for the recipient of androgenic alopecia 


\section{RESULTS}

Objective and subjective analysis of 40 patients in this study, Time of extraction was ranged from 1 hour to 4 hours according to donor \& numbers of graft reacquired to be harvested from the donor. Trichoscopy used in the analysis of density is showed in (Figure 15)

The total average time of operation was ranged from 2 hours in the post-traumatic or post-burn scar to (68 ) hours in androgenic male pattern alopecia.

Evaluation of density, length, and rate of regrowth was through using Trichoscope \& patient satisfaction was through a questionnaire on every follow up during the first 6 th months.
16-19). Study shows early good improvement in patients presented with post androgenic alopecia (Table 1) While marked improvement with using PRP in patients presented with post cicatricial alopecia in (Table 2)

The improvement has a reduction in post-operative recovery time for wound and soft tissue, Softening of in post cicatricial alopecia; and early increased in density and length were noticed with the group treated by PRP.

The hair starts with growth in groups with PRP earlier than without PRP groups, with no statistical difference at 6th months.

However, after a long period of follow up for one year, Study shows no difference in androgenic alopecia with using PRP or without its use.

The results of this study were evaluated using trichoscopy assessment all over the study. (Figures

\begin{tabular}{|c|c|c|c|c|c|c|c|}
\hline \multirow{2}{*}{\multicolumn{2}{|c|}{$6^{\text {th }}$ Month }} & \multicolumn{4}{|c|}{ androgenic alopecia AGA } & \multirow[t]{2}{*}{$\mathrm{X}^{2}$} & \multirow[t]{2}{*}{ p-value } \\
\hline & & \multicolumn{2}{|c|}{$\begin{array}{c}\text { PRP } \\
(\mathbf{N}=10)\end{array}$} & \multicolumn{2}{|c|}{$\begin{array}{c}\text { Non-PRP } \\
(\mathbf{N}=10)\end{array}$} & & \\
\hline \multirow{4}{*}{ Density } & (2) & 1 & $10 \%$ & 1 & $10 \%$ & \multirow[t]{4}{*}{18} & \multirow[t]{4}{*}{$<0.001 \mathrm{HS}$} \\
\hline & (3) & 0 & $0 \%$ & 1 & $10 \%$ & & \\
\hline & (4) & 0 & $0 \%$ & 8 & $80 \%$ & & \\
\hline & (5) & 9 & $90 \%$ & 0 & $0 \%$ & & \\
\hline \multirow{3}{*}{ Length } & (2) & 1 & $10 \%$ & 1 & $10 \%$ & \multirow[t]{3}{*}{18} & \multirow[t]{3}{*}{$<0.001 \mathrm{HS}$} \\
\hline & (4) & 0 & $0 \%$ & 9 & $90 \%$ & & \\
\hline & (5) & 9 & $90 \%$ & 0 & $0 \%$ & & \\
\hline Redness & No & 10 & $100 \%$ & 10 & $100 \%$ & ---- & ---- \\
\hline \multirow[t]{2}{*}{ Patient satisfaction } & Fair & 1 & $10 \%$ & 2 & $20 \%$ & \multirow[t]{2}{*}{0.392} & \multirow[t]{2}{*}{$0.531 \mathrm{NS}$} \\
\hline & Very good & 9 & $90 \%$ & 8 & $80 \%$ & & \\
\hline Rate of regrowth & & $\begin{array}{c}\text { Yes } \\
10\end{array}$ & $100 \%$ & $\begin{array}{c}\text { Yes } \\
10\end{array}$ & $100 \%$ & ---- & --- \\
\hline \multirow{2}{*}{$\begin{array}{c}\text { Complication } \\
\text { (at donor or recipient) }\end{array}$} & No & 9 & $90 \%$ & 10 & $100 \%$ & \multirow[t]{2}{*}{1.05} & \multirow[t]{2}{*}{$0.305 \mathrm{NS}$} \\
\hline & Yes & 1 & $10 \%$ & 0 & $0 \%$ & & \\
\hline
\end{tabular}

Table 1: Comparison of studied data in androgenic alopecia at $6^{\text {th }}$ month between PRP and non-PRP groups.

NB: We are giving indicator grade from 1 (less or poor) to 5 (full length or density) for density $1=$ less than 25 hair follicle per $1 \mathrm{~cm}^{2}, 2=25-30$ hair follicle per $1 \mathrm{~cm}^{2}, 3=30-35$ hair follicle per $1 \mathrm{~cm}^{2}, 4=35-40$ hair follicle per 1 $\mathrm{cm}^{2} \& 5=40-45$ hair follicle for $1 \mathrm{~cm}^{2}$, length ranged from 1 as starting of growth to 5 for full length.

Density and length which each of both examined and investigated by either trichoscopy or assessment by the surgeon.

This table shows:

A highly statistically significant difference ( $\mathrm{p}$-value $<0.001)$ between the PRP group and non-PRP group in androgenic alopecia at 6th months as regard density \& length.

No statistically significant difference ( $\mathrm{p}$-value $>0.05$ ) between PRP group and non-PRP group in androgenic alopecia at 6th months as regard Redness, patient satisfaction, and complications \& rate of regrowth. 


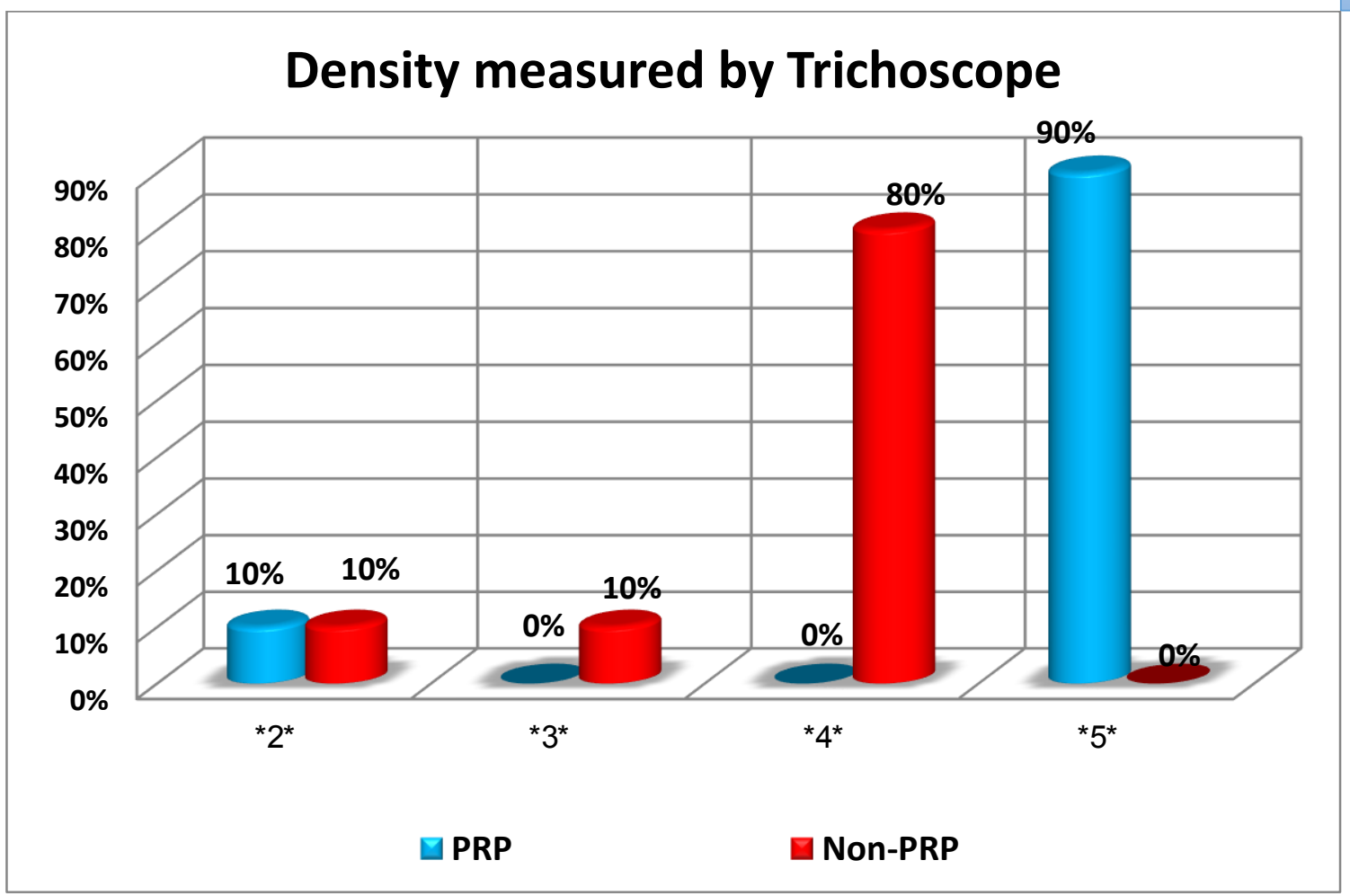

Fig. 16: Comparison of density in androgenic alopecia at $6^{\text {th }}$ month between PRP and non-PRP groups.

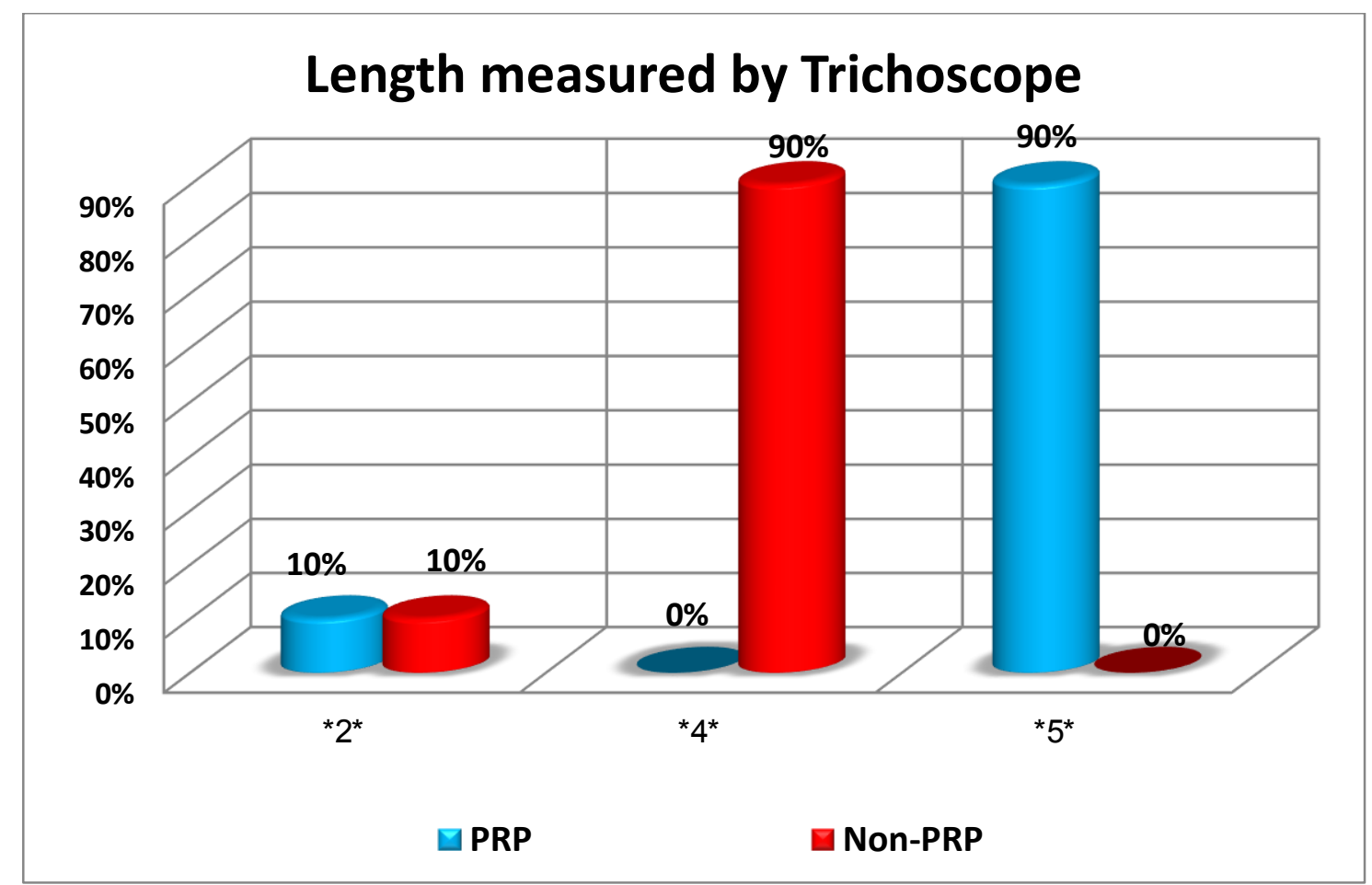

Fig. 17: Comparison of length in androgenic alopecia at $6^{\text {th }}$ month between PRP and non-PRP groups. 


\begin{tabular}{|c|c|c|c|c|c|c|c|}
\hline \multirow{2}{*}{\multicolumn{2}{|c|}{$6^{\text {th }}$ month }} & \multicolumn{4}{|c|}{ Cicatricial alopecia } & \multirow[t]{3}{*}{$\mathrm{X}^{2}$} & \multirow[t]{3}{*}{$\mathrm{p}$-value } \\
\hline & & \multicolumn{2}{|c|}{$\begin{array}{l}\text { PRP } \\
(\mathbf{N}=10)\end{array}$} & \multicolumn{2}{|c|}{$\begin{array}{l}\text { Non-PRP } \\
(\mathbf{N}=10)\end{array}$} & & \\
\hline \multirow{2}{*}{ Density } & (3) & 0 & $0 \%$ & 4 & $40 \%$ & & \\
\hline & (4) & 10 & $100 \%$ & 6 & $60 \%$ & 5 & $0.025 \mathrm{~S}$ \\
\hline \multirow{2}{*}{ Length } & (3) & 0 & $0 \%$ & 4 & $40 \%$ & \multirow{2}{*}{5} & \multirow[b]{2}{*}{$0.025 \mathrm{~S}$} \\
\hline & (4) & 10 & $100 \%$ & 6 & $60 \%$ & & \\
\hline Redness & No & 10 & $100 \%$ & 10 & $100 \%$ & ---- & ----- \\
\hline \multirow{3}{*}{ Patient satisfaction } & Fair & 0 & $0 \%$ & 4 & $40 \%$ & \multirow[t]{3}{*}{5.06} & \multirow[t]{3}{*}{$0.079 \mathrm{NS}$} \\
\hline & Good & 4 & $40 \%$ & 2 & $20 \%$ & & \\
\hline & Very good & 6 & $60 \%$ & 4 & $40 \%$ & & \\
\hline Rate of regrowth & & $\begin{array}{l}\text { Yes } \\
10\end{array}$ & $100 \%$ & $\begin{array}{l}\text { Yes } \\
6\end{array}$ & $60 \%$ & 5 & $0.025 \mathrm{~S}$ \\
\hline $\begin{array}{l}\text { Complication } \\
\text { (at donor } \\
\text { recipient) }\end{array}$ & No & 10 & $100 \%$ & 10 & $100 \%$ & & \\
\hline
\end{tabular}

Table 2: Comparison of studied data in Cicatricial alopecia at $6^{\text {th }}$ month between PRP and non-PRP groups.

This table shows:

A statistically significant difference (p-value $<0.05)$ between PRP group and non-PRP group in Cicatricial alopecia at 6th months as regard density, rate of regrowth, and length.

No statistically significant difference (p-value > 0.001) between the PRP group and non-PRP group in

Cicatricial alopecia at 6th months as regard Redness, patient satisfaction, and complications.

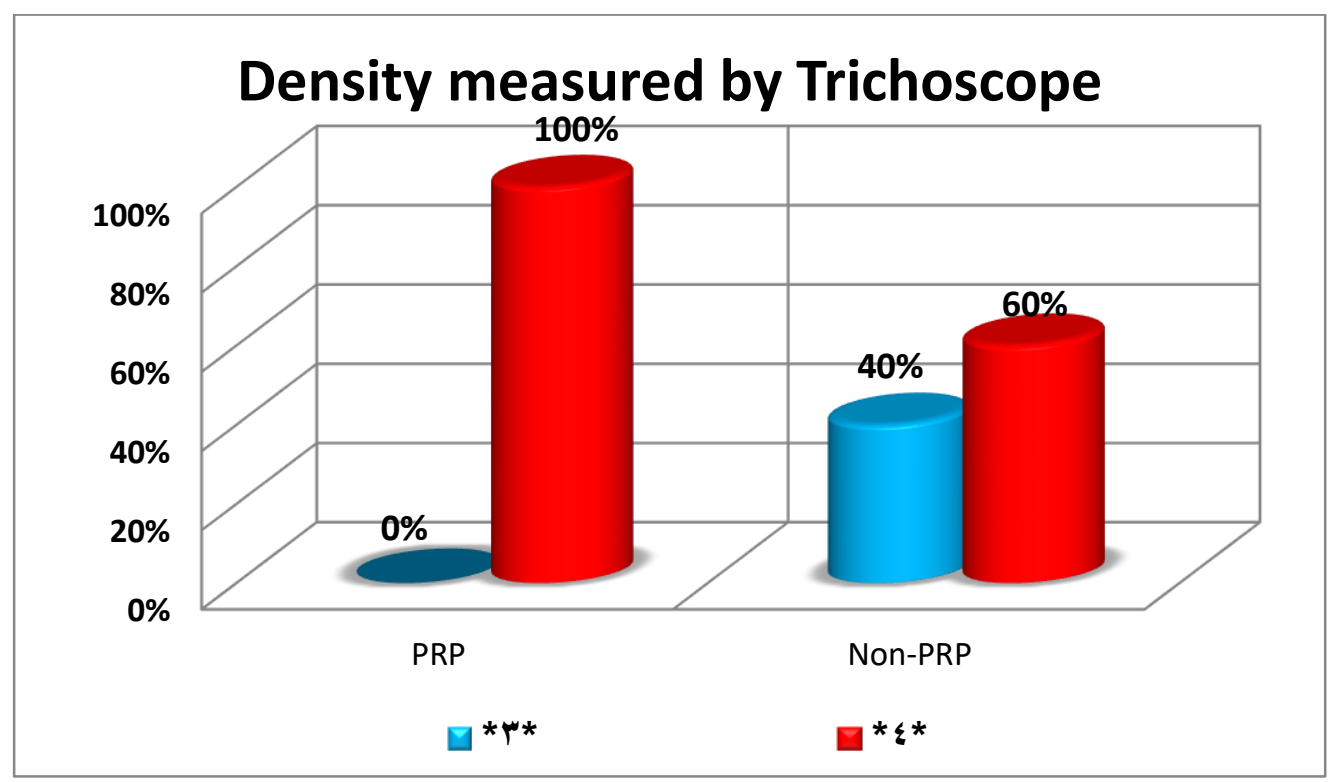

Fig. 18: Comparison of density in Cicatricial alopecia at $6^{\text {th }}$ month between PRP and non-PRP groups. 


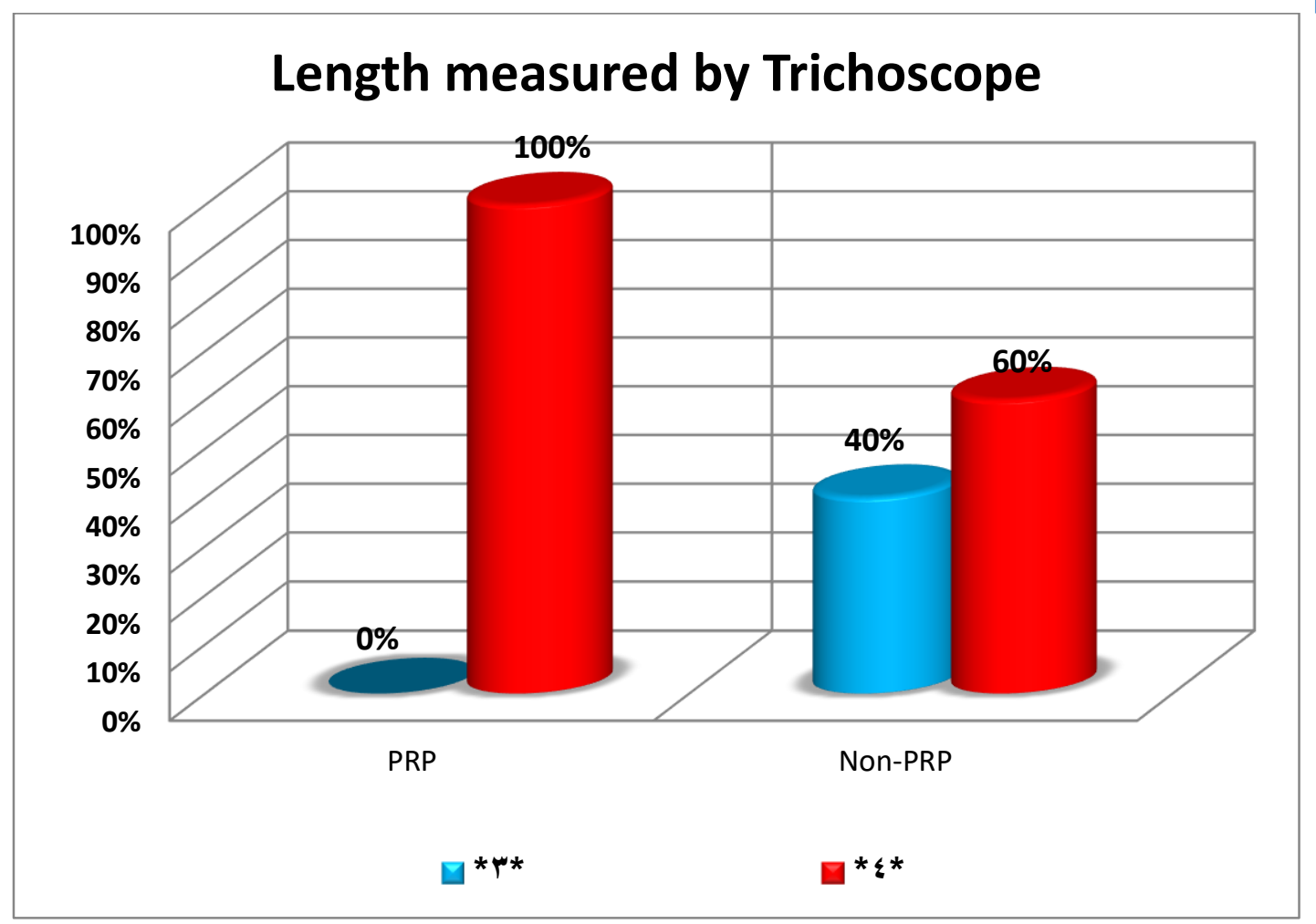

Fig. 19: Comparison of length in Cicatricial alopecia at $6^{\text {th }}$ month between PRP and non-PRP groups.

\section{DISCUSSION}

Onestage FUE hair transplantation of scalp alopecia has been demonstrated by many studies

Male pattern baldness happens in a specific pattern and it impacts adolescents as well as adults. Polygenic heredity is considered to be its cause. Also, male hormone testosterone plays a major role, the hormone binds to the androgenic receptor on hair follicle leading to early entry to telogen phase and inducing hair fall. ${ }^{9 \notin 10}$

Probably the most significant short-term failure with FUE is seen with an inability to align the grafts as the punch advances at the correct angle. Although this problem is easily recognized with good quality control systems in place, many doctors do not routinely examine their FUE extraction quality during the surgery. Microscopic examination of each extracted graft will identify every anatomic element of the follicular unit and if these elements are damaged. ${ }^{11}$

Our study agrees with the previous study reported by Rassmanet al. ${ }^{11}$, the learning curve of the new surgeons joining us for learning at our department at Al Azhar University hospitals. Difficulties were mainly in the reduction of the total time of either extraction or implantation \& perfection with good quality of harvested grafts. And how to avoid transaction rate and overheating by increasing motor speed which leads to damage of grafts also handling of grafts makes a great challenge to achieve better results.

Researchers as Rassmanet al. ${ }^{11}$ considered that FUE Mega sessions defined as FUE graft numbers that exceed 1000 grafts. At mega sessions, in agreement with our study, we should take the grafts from safe donor areas to avoid its future loss in the recipient area. ${ }^{11}$

In agreement with Sexanaet al. ${ }^{7}$ who observed that the quality of scarred tissue improved after transplantation with adding PRP therapy, as the skin atrophy appeared to be reduced in the cicatricial areas. This can be possibly explained by the action of the PRP and additionally, the transplanted hair themselves cause neovascularization and dermal reorganization. ${ }^{7}$

In our study; adding PRP therapy with post cicatricial alopecia hair transplantation gives the patient more advances with high patient satisfaction in scar quality, hair density \& length results which are evaluated by patient questionnaire 6th month's post-operative follow up when compared with other groups without PRP therapy.

Our study can explain and in agreement with Uebel et al. ${ }^{5}$, that PRP with its action of tissue regeneration and remodeling with angiogenesis has the potential to revitalize the scarred tissue, improve its 
vascularity to make it more receptible for transplant and help increase the donor yield. Such PRP can serve as an adjuvant to hair transplant in compromised recipient areas as seen in scarring alopecias. ${ }^{5}$

Data present in this study suggested that uses of PRP regimen protocol after FUE hair transplantation show good outcome with reduction of postoperative recovery time $\&$ early results was noticed on groups treated with post-operative PRP in comparison to other groups not managed with the post-operative regimen of PRP injections.

Uebel et al. ${ }^{5}$, observed a significant difference in the areas treated with platelet plasma growth factors with increased density in these areas when compared to other areas not treated with PRP or other control patients. ${ }^{5}$

In our study, our results show the same with a highly statistically significant difference ( $\mathrm{p}$-value < 0.001 ) between the PRP group and non-PRP group in androgenic alopecia at 6th months as regard density \& length. A statistically significant difference ( $\mathrm{p}$-value $<0.05$ ) between the PRP group and non-PRP group in Cicatricial alopecia at 6th months as regard density, and length.

Garg $^{6}$, study the outcome of intra-operative injected platelet-rich plasma therapy during follicular unit extraction hair transplantation for 40 patients. In PRP-treated group (20 patients), the number of the patient it is having multiple grafts was significantly higher as compared to non-PRP treated group (20 patients) and in PRP-treated group, 65\% of the patient had more than $10 \mathrm{~mm}$ hair shaft length. While in the non-PRP treated group, only $10 \%$ of the patient had more than $10 \mathrm{~mm}$ shaft length. ${ }^{6}$ Despite that we didn't inject PRP intraoperatively in our study but the result was the same obtained by Garg study.

However, in androgenic alopecia group results shows early (up to 6 months) marked differences with good results in the group using PRP regimen therapy. It was similar to what noticed by Garg 2016.

Garg', noticed after 3 months of hair transplantation, in the PRP group, all the twenty patients had multiple grafts starting regrowth and erupting out. Whereas in the non-PRP group, only $60 \%$ of patients had multiple grafts which increased to $80 \%$ at 6 months.

Also in our study, we noticed the same results mainly on cicatricial alopecia. PRP decreases the time of regrowth and appearance of grafts again at the end of 6th months about $100 \%$ of the PRP treated group. A statistically significant difference (p-value < 0.05) when compared to the non-PRP group only $60 \%$ of regrowth achieved at 6th months.
But after a year follows up of many patients with an androgenic alopecia group there is no difference between using the PRP regimen or not.

We reported that for optimum results not only the PRP injections are important but also the handling of grafts, storage, techniques of harvesting of grafts, and the total time of operation makes a big difference in FUE hair transplantation for scalp alopecia after 1 year follow up.

\section{CONCLUSION}

PRP therapy after hair transplantation is beneficial in giving faster density with the reduction in recovery period post cicatricial alopecia, with no benefit in FUE hair transplantation in cases with androgenic alopecia. So we recommend using PRP in post cicatricial alopecia

\section{REFERENCES}

1. Araújo, R., Fernandes, M., Cavaco-Paulo, A., \& Gomes, A Biology of Human Hair: Know Your Hair to Control It. In Biofunctionalization of Polymers and their Applications, 2010; (pp. 121-143). Springer Berlin Heidelberg. https://doi.org/10.1007/10_2010_88

2. David Chan and YadrankoDucic, An Update on Hair Restoration. Journal of Aesthetic \& Reconstructive Surgery; 2015, Vol. 1 No. 1: 8, DOI: 10.4172/2472-1905.10008.

3. Bicknell LM, Kash N, Kavouspour C, Rashid RM, Follicular unit extraction hair transplant harvest: A review of current recommendations and future considerations. 2014; Dermatol Online J 2014;20. PII: Doj_21754.

4. Parsley, William \& Perez-Meza, David. Review of Factors Affecting the Growth and Survival of Follicular Grafts. Journal of cutaneous and aesthetic surgery, 2010; 3. 6975. 10.4103/0974-2077.69014.

5. Uebel CO, da Silva JB, Cantarelli D, Martins $\mathrm{P}$. The role of platelet plasma growth factors in male pattern baldness surgery. PlastReconstrSurg 2006;118:1458-67. †

6. Garg, S. Outcome of intra-operative injected platelet-rich plasma therapy during follicular unit extraction hair transplant: A prospective randomized study in forty patients. Journal of Cutaneous and Aesthetic Surgery, 2016; 9(3), 157.https://doi.org/10.4103/0974-2077.191657.

7. Saxena K, Saxena DK, Savant SS. Successful hair transplant outcome in cicatricial lichen planus of the scalp by combining scalp and beard hair along with platelet-rich plasma. $J$ CutanAesthetSurg 2016;9:51-5

8. Garg, A., \& Garg, S. Donor harvesting: Follicular unit excision. Journal of Cutaneous and Aesthetic Surgery; 2018, 11(4), 195. https://doi.org/10.4103/jcas.jcas_123_18 
9. Jain R, De-Eknamkul W. Potential targets in the discovery of new hair growth promoters for androgenic alopecia, Expert OpinTher Targets; 2014,18:787-806.

10. Cervelli V, Garcovich S, Bielli A, Cervelli G, Curcio BC, Scioli MG, et al. The effect of autologous activated platelet-rich plasma (AAPRP) injection on pattern hair loss: Clinical and histomorphometric evaluation. Biomed Res Int 2014; 2014:760709.

11. Rassman, W., \& Pak, J. Follicular Unit Extraction: Evolution of a Technology. Journal of Transplantation Technologies \& Research, 2016; 6 (2). https://doi.org/10.4172/21610991.1000158 